\title{
Species distribution and susceptibility profile of Candida species in a Brazilian public tertiary hospital
}

\author{
Ariane Bruder-Nascimento ${ }^{1}$, Carlos Henrique Camargo ${ }^{1}$, Maria Fátima Sugizaki ${ }^{1}$, Terue Sadatsune ${ }^{1}$, \\ Augusto Cezar Montelli ${ }^{1}$, Alessandro Lia Mondelli ${ }^{2}$, Eduardo Bagagli ${ }^{1 *}$
}

\begin{abstract}
Background: Species identification and antifungal susceptibility tests were carried out on 212 Candida isolates obtained from bloodstream infections, urinary tract infections and dialysis-associated peritonitis, from cases attended at a Brazilian public tertiary hospital from January 1998 to January 2005.

Findings: Candida albicans represented 33\% of the isolates, Candida parapsilosis 31.1\%, Candida tropicalis 17.9\%, Candida glabrata $11.8 \%$, and others species 6.2\%. In blood culture, C. parapsilosis was the most frequently encountered species (48\%). The resistance levels to the antifungal azoles were relatively low for the several species, except for C. tropicalis and C. glabrata. Amphotericin B resistance was observed in 1 isolate of C. parapsilosis.

Conclusions: The species distribution and antifungal susceptibility herein observed presented several epidemiological features common to other tertiary hospitals in Latin American countries. It also exhibited some peculiarity, such as a very high frequency of C. parapsilosis both in bloodstream infections and dialysis-associated peritonitis. C. albicans also occurred in an important number of case infections, in all evaluated clinical sources. C. glabrata presented a high proportion of resistant isolates. The data emphasize the necessity to carry out the correct species identification accompanied by the susceptibility tests in all tertiary hospitals.
\end{abstract}

\section{Findings}

Infections caused by opportunistic pathogens, such as yeasts, are becoming important causes of morbidity and mortality in many patients, because of alterations in the immune system and invasive hospital procedures [1]. Candidemia is commonly associated with high morbidity and mortality resulting in significant increases in the length of patients' hospitalization and in healthcare costs [2].

In the past two decades, nosocomial yeast infections have increased significantly worldwide [3]. In the United States, yeast infection ranks as the 4th most common cause of nosocomial bloodstream infection (BSI) [3]. In Brazil, Candida albicans, Candida tropicalis and Candida parapsilosis are the most common species isolated from BSI in several medical centers $[2,4,5]$. There has been an important shift in the species causing

\footnotetext{
* Correspondence: bagagli@ibb.unesp.br

${ }^{1}$ Botucatu Biosciences Institute, Sao Paulo State University, Botucatu, Brazil
}

nosocomial candidemia, with the emergence of nonalbicans species, particularly those more resistant to antifungal drugs $[6,7]$. Although studies demonstrate that antifungal resistance is relatively rare $[2,4,8]$, antifungal drugs have been used intensively either to control such infections or as prophylactic in long-term treatments, creating serious worries that might select for drug resistances, thus greatly harming infection control $[9,10]$. Candida species have various degrees of susceptibility to the frequently used antifungal drugs. For example, while Candida krusei is intrinsically resistant to fluconazole, Candida glabrata is less susceptible or has higher MICs than other Candida species [10], which makes the correct species identifications and susceptibility tests pressing necessities.

In the present work, we present data on species frequency and antifungal susceptibility of Candida isolates obtained in a Brazilian public tertiary hospital.

(c) 2010 Bagagli et al; licensee BioMed Central Ltd. This is an open access article distributed under the terms of the Creative Commons 


\section{Results}

\section{Species identification}

Table 1 demonstrates the species distribution of Candida isolates. In a total of 212 yeast cultures, 70 (33\%) were isolates of C. albicans, 66 (31.8\%) C. parapsilosis, 38 (17.9\%) C. tropicalis, 25 (11.8\%) C. glabrata, 10 (4.7\%) C. guilliermondii, 2 (0.9\%) C. lusitaniae and 1 (0.5\%) C. pelliculosa. With regard to clinical materials, C. parapsilosis was the species most commonly isolated from bloodstream infections (BSI) and also from peritoneal fluid (PF), while C. albicans presented a homogeneous distribution among the three sources, BSI, PF and urinary tract infections (UTI). C. tropicalis and C. glabrata were observed mainly in UTI isolates.

\section{Susceptibility tests}

Susceptibility tests for fluconazole, itraconazole and amphotericin B were performed on 212 isolates of Candida species. Table 2 summarizes the MIC ranges that delimit inhibition of isolates at proportions of 50 and $90 \%$, determined by visual inspection, after $48 \mathrm{~h}$ incubation. Among all evaluated isolates, including C. glabrata, $31(14.6 \%)$ were resistant to fluconazole, $43(20.3 \%)$ to itraconazole and $1(0.5 \%)$ to amphotericin $\mathrm{B}$. When excluding this species the resistant isolates decrease to $14(7.8 \%)$ and $21(11.2 \%)$ for fluconazole and itraconazole, respectively.

Fluconazole exhibited the greatest activity against $C$. albicans with resistance observed in 5 (7.1\%) isolates. Seven (18.4\%) C. tropicalis, 1(1.5\%) C. parapsilosis, 17 (68\%) C. glabrata and 1 (10\%) C. guilliermondii isolates were resistant to fluconazole. Resistance to itraconazole was found in 8 (10\%) C. albicans, 22 (88\%) C. glabrata, 2 (3\%) C. parapsilosis, $10(21.1 \%)$ C. tropicalis and 1 (10\%) C. guilliermondii isolates. One C. parapsilosis isolate was amphotericin B-resistant. Isolates of C. lusitaniae and C. pelliculosa were susceptible to amphotericin $\mathrm{B}$ and to the azoles.

\begin{tabular}{|c|c|c|c|c|}
\hline Species & $\begin{array}{c}\text { BSI } \\
\%(n)\end{array}$ & $\begin{array}{c}\text { UTI } \\
\% \text { (n) }\end{array}$ & $\begin{array}{c}\text { PF } \\
\%(n)\end{array}$ & $\begin{array}{l}\text { Total } \\
\%(n)\end{array}$ \\
\hline C. albicans & $32.4(33)$ & $34.1(29)$ & $32.0(8)$ & $33.0(70)$ \\
\hline C. glabrata & $4.9(5)$ & $23.5(20)$ & - & $11.8(25)$ \\
\hline C. guilliermondii & $6.9(7)$ & $1.2(1)$ & $8.0(2)$ & 4.7 (10) \\
\hline C. lusitaniae & $2.0(2)$ & - & - & $0.9(2)$ \\
\hline C. parapsilosis & $48.0(49)$ & $8.2(7)$ & $40.0(10)$ & $31.1(66)$ \\
\hline C. pelliculosa & $1.0(1)$ & - & - & $0.5(1)$ \\
\hline C. tropicalis & $4.9(5)$ & $32.9(28)$ & $20.0(5)$ & $17.9(38)$ \\
\hline Total & 102 & 85 & 25 & 212 \\
\hline
\end{tabular}

The MIC for fluconazole, itraconazole and amphotericin B of the QC strains ranged, respectively, from 1-4 $\mu \mathrm{g} / \mathrm{mL}, 0.12-0.5 \mu \mathrm{g} / \mathrm{mL}$ and $0.5-1 \mu \mathrm{g} / \mathrm{mL}$, for Candida parapsilosis ATCC 22019, and from 16-128 $\mu \mathrm{g} / \mathrm{mL}$, $0.25-1 \mu \mathrm{g} / \mathrm{mL}$ and $1-4 \mu \mathrm{g} / \mathrm{mL}$ for Candida krusei ATCC 6258.

\section{Discussion}

The epidemiology of Candida infections has been extensively studied in North America and Europe [11], where large surveillance programs exist. In Latin America, these data are limited [2], with some regional studies in a few medical centers $[4,5]$. Colombo et al. [2] carried out the largest multicenter study in eleven medical centers of nine Brazilian cities; however, our hospital was not included in their study, and the data shown herein presented some peculiar differences both in the species frequency and in the susceptibility profile. The Botucatu Clinical Hospital is a regional state medical center that characteristically attends to a high proportion of patients from small communities and rural areas, with low access to medical assistance and low income, who are mainly in critical condition or in need of some advanced medical procedures, such as dialysis or chemotherapy. Consistent with several previous studies $[2,4,5]$, the frequency of non-albicans species herein observed was greater than C. albicans. C. parapsilosis was the species most often isolated from BSI and PF, whose frequencies (43 and 40\%) were higher than those observed in the previous Brazilian multicenter studies (7-40\% in BSI) $[2,4,5]$. A peculiar species distribution was found in relation to the clinical sources. While in BSI and PF $C$. parapsilosis appears as the leading species, followed by C. albicans and C. tropicalis, in UTI, C. albicans occurs more frequently, followed by C.tropicalis and C. glabrata. Our findings confirm other studies that indicate $C$. parapsilosis as one of the most important species causing candidemia [2-8]. At the same time, the data also indicate that C. glabrata occurs less frequently, in substantial contrast to temperate countries of North America and Europe [11]. The predominance of $C$. parapsilosis in the peritoneal fluid under our casuistry also comes as no surprise, considering that this species appears to be common mainly in Latin America, and in other countries in patients receiving peritoneal dialysis $[12,13]$. The reasons why C. parapsilosis occurs more frequently in Latin American countries is not completely understood. C. parapsilosis is considered a commensal of human skin since it has been isolated from the hands of health workers [14], who have been identified as the major vectors in the infection acquisition [15]. At the same time, other local epidemiological factors also may make important contributions to the high frequency of C. parapsilosis in BSI and PF, such as a high proportion 
Table 2 In vitro activity of antifungal agents against Candida spp. isolates from different clinical materials at the Brazilian Tertiary Hospital (Clinical Hospital of the UNESP School of Medicine, Botucatu, São Paulo State), from 1998 to 2005.

\begin{tabular}{|c|c|c|c|c|c|c|c|c|c|c|c|c|c|c|c|}
\hline \multirow[t]{2}{*}{ Isolates (n) } & \multirow[t]{2}{*}{ Drugs $^{a}$} & \multicolumn{14}{|c|}{ Cumulative $\%$ of isolates susceptible at a MIC $(\mathrm{g} / \mathrm{ml})$ of $^{\mathrm{d}}$ : } \\
\hline & & $0.03^{b}$ & 0.06 & $0.125^{c}$ & $0.25^{\mathrm{a}}$ & 0.5 & 1 & 2 & 4 & 8 & 16 & $>16^{c}$ & 32 & 64 & $>64^{b}$ \\
\hline \multirow[t]{3}{*}{ C. albicans (70) } & FLU & & & 5.7 & 30.0 & 40.0 & 65.7 & 74.3 & 80.0 & 84.3 & 92.9 & & & & 100 \\
\hline & ITR & 57.1 & 71.4 & 84.3 & 87.1 & 88.6 & 88.6 & 90.0 & 90.0 & 90.0 & 90.0 & 100 & & & \\
\hline & $\mathrm{AMB}$ & & & & 21.0 & $\underline{64.0}$ & 100 & & & & & & & & \\
\hline \multirow[t]{3}{*}{ C. glabrata (25) } & FLU & & & & & & & 4.0 & & & 16.0 & & 32.0 & 92.0 & 100 \\
\hline & ITR & & 4.0 & 4.0 & 8.0 & 12.0 & 32.0 & 48.0 & $\underline{56.0}$ & 60.0 & 76.0 & 100 & & & \\
\hline & $\mathrm{AMB}$ & & & & & 16.0 & 100 & & & & & & & & \\
\hline \multirow[t]{3}{*}{ C. guilliermondii (10) } & FLU & & & & & & & 30.0 & 30.0 & $\underline{80.0}$ & 90.0 & 90.0 & 90.0 & 100,0 & \\
\hline & ITR & 20.0 & $\underline{50.0}$ & 60.0 & 90.0 & 90.0 & 90.0 & 90.0 & 90.0 & 90.0 & 90.0 & 100 & & & \\
\hline & $\mathrm{AMB}$ & & & & 10.0 & 30.0 & $\underline{100}$ & & & & & & & & \\
\hline \multirow[t]{3}{*}{ C. parapsilosis (66) } & FLU & & & 1.5 & 3.0 & 10.6 & 33.3 & $\underline{69.7}$ & 89.4 & 98.5 & 98.5 & 98.5 & 98.5 & 100 & \\
\hline & ITR & $\underline{69.7}$ & 90.9 & 97.0 & 97.0 & 98.5 & 98.5 & 98.5 & 98.5 & 98.5 & 98.5 & 100 & & & \\
\hline & $\mathrm{AMB}$ & & & & 1.5 & 6.1 & $\underline{98.5}$ & 100 & & & & & & & \\
\hline \multirow[t]{3}{*}{ C. tropicalis (38) } & FLU & & & 2.6 & 7.9 & 31.6 & 44.7 & $\underline{60.5}$ & 76.3 & 81.6 & 81.7 & 81.8 & 81.9 & 81.10 & 100 \\
\hline & ITR & 21.1 & 31.6 & $\underline{55.3}$ & 68.4 & 73.7 & 78.9 & 84.2 & 84.2 & 84.2 & 84.2 & 100 & & & \\
\hline & $\mathrm{AMB}$ & & & & & 21.0 & $\underline{100}$ & & & & & & & & \\
\hline \multirow[t]{3}{*}{ All Candida species $^{\mathrm{e}}(212)$} & $F L U^{a}$ & & & 2.8 & 11.3 & 17.9 & 37.7 & $\underline{57.1}$ & 67.9 & 80.7 & 86.3 & 88.2 & $\underline{94.3}$ & 100 & \\
\hline & $\mathrm{ITR}^{\mathrm{b}}$ & 45.3 & $\underline{61.3}$ & 72.2 & 77.8 & 79.7 & 83.0 & $\overline{86.3}$ & 87.3 & 87.7 & 90.1 & 100 & & & \\
\hline & $\mathrm{AMB}$ & & & & 8.0 & 30.7 & $\underline{99.5}$ & 100 & & & & & & & \\
\hline
\end{tabular}

${ }^{\mathrm{a}}$ FLU: fluconazole, ITR: itraconazole, AMB: amphotericin B; ${ }^{\mathrm{b}}$ Fluconazole drug concentrations was evaluated from 0.125 to $64 \mu \mathrm{mg} / \mathrm{ml} ;{ }^{\mathrm{c}}$ Itraconazole and amphotericin B drug concentrations were evaluated from 0.03 to $16 \mu \mathrm{g} / \mathrm{ml}$; ${ }^{d}$ Values corresponding to MICs at which at least $50 \%$ of isolates are inhibited are listed in underlined type and $90 \%$ in bold type; ${ }^{e}$ Included 2 C. lusitaniae (FLU 2.0, ITRA 0.06; AMB 1.0) and 1 C. pelliculosa (FLU 2.0, ITRA 0.25; AMB 0.5).

of neonates in the casuistry, as suggested by Weems [16], as well as the intense use of vascular catheters, parenteral nutrition and peritoneal dialysis procedures [17].

The isolation of C. pelliculosa, the asexual form of Pichia anomala, and C. lusitaniae, both rarely causing BSI, was found in other medical reports from Brazil $[2,18]$ and other countries $[19,20]$. C. guilliermondii, also considered a normal component of human skin and mucosal flora and less common in the northern hemisphere, has been more frequently isolated in Latin America and presented reduced susceptibility to fluconazole $[21,11,2]$.

In the present study, most of the isolates were susceptible to the antifungal drugs tested. Resistance to fluconazole and itraconazole was observed relatively high, mainly in isolates of C. glabrata, C. tropicalis and C. albicans. Similar to other studies, the percentage of isolates resistant to fluconazole was smaller than to itraconazole $[22,23]$. As expected, high secondary resistance rates were observed in C. glabrata to fluconazole (68\%) and itraconazole (88\%); this resistance to multiple azoles has been explained by an upregulation of CDR genes that encode the CDR efflux pumps [24]. Herein one of nine isolates of C. guilliermondii presented resistance to the both azole drugs, and high levels of resistance in $C$. guilliermondii has been observed worldwide [25]. The fact that resistance to amphotericin B was observed in one isolate of $C$. parapsilosis is controversial since most studies report a lack of amphotericin $B$ resistance in Candida species $[2,20,26]$, while other studies also found resistance to this drug in C. parapsilosis $[4,27]$. Amphotericin B is used most commonly in several Brazilian public tertiary hospitals in the treatment of systemic mycosis, in which the patients remain hospitalized for long periods of treatments, as in our hospital for paracoccidiodomycosis [28]. The possible effect of this drug against selectively resistant Candida species should not be excluded and merits proper evaluation.

In conclusion, the species distribution and antifungal susceptibility observed herein present several epidemiological features common to those observed in other tertiary hospitals in various Latin American countries, 
although also exhibit some peculiarities, such as a very high frequency of $C$. parapsilosis both in BSI and PF. $C$. albicans continues to occur in an important number of infection cases, with homogeneous distribution among all the evaluated clinical sources. C. glabrata presents a high proportion of resistant isolates, which reinforces the necessity to carry out the correct species identification in association with the susceptibility tests.

\section{Methods}

\section{Origin of isolates}

A total of 212 clinical isolates of Candida spp., isolated from bloodstream infections - BSI (102 isolates), urinary tract infections - UTI (85 isolates) and and peritoneal fluid - PF (25 isolates), obtained from patients from Clinical Hospital of the UNESP School of Medicine, Botucatu, São Paulo State, between January 1998 and January 2005 were evaluated in the study. The criteria and/or condition for the selection of Candida isolates to be analyzed were: i) the patients must be presenting clinical evidence of infection; ii) the materials from blood and peritoneal fluid were always collected by sterile puncture; iii) the positive cultures both from blood and peritoneal fluid were obtained in BACTEC System (BD Microbiology, Cockeysville, MD), followed by plating culture and identification by microscopy, biochemical tests and VITEK.ONE ${ }^{\oplus}$ (BioMérieux, Durham, NC); iv) for the urine, the patients also must present clinical evidence of infection, the materials were collected in sterile cups from midstream urine specimen obtained after cleansing the external urethral meatus, cultured in MacConkey (Oxoid, Basingstoke, UK), Lactose Electrolyte Deficient agar (CLED; Oxoid,. Basingstoke, UK) and Sabouraud dextrose (Oxoid, Basingstoke, UK) agar plates, with counts equal to or above $10^{4}$ colonies per $\mathrm{ml}$. The peritoneal fluid materials were collected from patients in continuous ambulatory peritoneal dialysis (CAPD) by sterile puncture and we did not include samples from drainage tubes or bags. Repetitive isolates from the same patient were not included. All isolates were stored, in vial tubes containing Brain Heart Infusion plus $10 \%$ glycerol, in a freezer at $-80^{\circ} \mathrm{C}$. At the moment of the study each isolate was cultured on Sabouraud dextrose agar plates at $35^{\circ} \mathrm{C}$.

\section{Species identification}

All Candida species isolates were re-identified based on colony morphology on Chromogenic agar (CHROMagar Candida, Difco), microscopy features on Corn-meal agar slide culture, as well as the assimilation and fermentation tests.

\section{Susceptibility testing}

Reference antifungal susceptibility testing of all 212 isolates was performed by BMD (broth microdilution) exactly as described in CLSI document M27-A2 [29] against fluconazole (Pfizer, Sao Paulo, Brazil), itraconazole (Janssen, Beerse, Belgium) and amphotericin B (Sigma, St. Louis, MO, USA). The isolates were incubated at $35^{\circ} \mathrm{C}$ and the presence or absence of growth, after $48 \mathrm{~h}$, was observed by visual inspection. The MIC endpoint for amphotericin B was considered the lowest tested drug concentration able to prevent any visible growth, while the MIC for azoles was considered the lowest tested drug concentration causing a significant reduction (approximately 50\%) in growth compared to the growth of the drug-free positive control [29]. MIC interpretations follow the CLSI breakpoints [29] for fluconazol ( $\leq 8 \mathrm{ug} / \mathrm{ml}$, susceptible; $16-32 \mathrm{ug} / \mathrm{ml}$, SDD, $\geq 64$, resistant) and itraconazole $(\leq 0.125 \mu \mathrm{g} / \mathrm{ml}$, susceptible; 0.25-0.5 ug/ml, SDD, $\geq 1$, resistant). For amphotericin B, due to a lack of consensus about the definition of this drug's MIC, previous interpretative breakpoints described elsewhere [30] were employed ( $\leq 1 \mathrm{ug} / \mathrm{ml}$, susceptible, $\geq 2$, resistant).

\section{Quality control}

QC was performed for BMD in accordance with CLSI documents M27-A2 [29] by using Candida krusei ATCC 6258 and Candida parapsilosis ATCC 22019.

\section{List of abbreviations}

BSI: bloodstream infection; UTI: urinary tract infection; PF: peritoneal fluid; CAPD: continuous ambulatory peritoneal dialysis; BMD: Broth microdilution.

\section{Acknowledgements}

We thank the staff of the Laboratory of Medical Microbiology at the Clinical Hospital of the UNESP School of Medicine, Botucatu, São Paulo State, for kindly providing the isolates. The study was financially supported by Fundação de Amparo à Pesquisa do Estado de São Paulo (FAPESP; grant number 2007/01946-4).

\section{Author details}

'Botucatu Biosciences Institute, Sao Paulo State University, Botucatu, Brazil. ${ }^{2}$ Medical School, Sao Paulo State University, Botucatu, Brazil.

\section{Authors' contributions}

$\mathrm{ABN}$ and $\mathrm{CHC}$ carried out the laboratory experiments, tabulated the data and drafted the manuscript. MFS, ALM and TS participated in the design of the study and in the discussion. ACM conceived the study. EB participated in its design and coordination and helped to draft the manuscript. All authors read and approved the final manuscript.

\section{Competing interests}

The authors declare that they have no competing interests.

Received: 28 April 2009

Accepted: 3 January 2010 Published: 3 January 2010

\section{References}

1. White TC, Marr KA, Bowden RA: Clinical, cellular, and molecular factors that contribute to antifungal drug resistance. Clin Microbiol Rev 1998, 11:382-402.

2. Colombo AL, Nucci M, Park B J, Nouér SA, Arthington-Skaggs B, da Matta DA, Warnock D, Morgan J: Epidemiology of candidemia in Brazil: a nationwide sentinel surveillance of candidemia in eleven medical centers. J Clin Microbiol 2006, 44:2816-2823. 
3. Wisplinghoff $H$, Bischoff $T$, Tallent SM, Seifert $H$, Wenzel RP, Edmond MB: Nosocomial bloodstream infections in US hospitals: analysis of 24,179 cases from a prospective nationwide surveillance study. Clin Infect Dis 2004, 39:309-317.

4. Passos XS, Costa CR, Araújo CR, Nascimento ES, e Souza LK, Fernandes Ode F, Sales WS, Silva Mdo R: Species distribution and antifungal susceptibility patterns of Candida spp. bloodstream isolates from a Brazilian tertiary care hospital. Mycopathologia 2007, 163:145-151.

5. Medrano DJ, Brilhante RS, Cordeiro AR, Rocha MF, Rabenhorst SH, Sidrim JJ: Candidemia in a Brazilian hospital: the importance of Candida parapsilosis. Rev Inst Med Trop Sao Paulo 2006, 48:17-20.

6. Snydman DR: Shifting in patterns in the epidemiology of nosocomial Candida infections. Chest 2003, 123:500-503.

7. Sobel JD: The emergence of non-albicans Candida species as causes of invasive candidiasis and candidemia. Curr Infct Dis Rep 2006, 8:427-433.

8. Aquino VR, Lunardi LW, Goldani LZ, Barth AL: Prevalence, susceptibility profile for fluconazole and risk factors for candidemia in a tertiary care hospital in Southern Brazil. Braz J Infect Dis 2005, 9:411-418.

9. Pfaller MA, Diekema DJ, Messer SA, Boyken L, Hollis RJ: Activities of fluconazole and voriconazole against 1,586 recent clinical isolates of Candida species determined by Broth microdilution, disk diffusion, and Etest methods: report from the ARTEMIS Global Antifungal Suscetibility Program, 2001. J Clin Microbiol 2003, 41:1440-1446.

10. Yang $Y L, H o$ YA, Cheng HH, Ho M, Lo HJ: Susceptibilities of Candida species to amphotericin $B$ and fluconazole: the emergence of fluconazole resistance in Candida tropicalis. Infect Control Hosp Epidemiol 2004, 25:60-64.

11. Pfaller MA, Boyken L, Hollis RJ, Kroeger J, Messer SA, Tendolkar S, Diekema DJ: In vitro susceptibility of invasive isolates of Candida spp. to anidulafungin, caspofungin, and micafungin: six years of global surveillance. J Clin Microbiol 2008, 46:150-156.

12. Wang AY, Yu AW, Li PK, Lam PK, Leung CB, Lai KN, Lui SF: Factors predicting outcome of fungal peritonitis in peritoneal dialysis: analysis of a 9-year experience of fungal peritonitis in a single center. Am J Kidney Dis 2000, 36:1183-1192.

13. Manzano-Gayosso P, Hernandez-Hernandez F, Mendez-Tovar LJ, GonzalezMonroy J, Lopez-Martinez R: Fungal peritonitis in 15 patients on continuous ambulatory peritoneal dialysis (CAPD). Mycoses 2003, 46:425429.

14. Asbeck ECV, Huang YC, Markham NA, Clemons CV, Stevens DA: Candida parapsilosis fungemia in neonates: genotyping results suggest healthcare workers hands as source, and review of published studies. Mycopathologia 2007, 164:287-293.

15. Trofa D, D Gácser A, Nosanchuk JD: Candida parapsilosis, an emerging fungal pathogen. Clin Microbiol Rev 2008, 21:606-625.

16. Weems JJ: Candida parapsilosis: epidemiology, pathogenicity, clinical manifestations, and antimicrobial susceptibility. Clin Infect Dis 1992, 14:756-766.

17. Girmenia C, Martino P, De BF, Gentile G, Boccanera M, Monaco M, Antonucci G, Cassone A: Rising incidence of Candida parapsilosis fungemia in patients with hematologic malignancies: clinical aspects, predisposing factors, and differential pathogenicity of the causative strains. Clin Infect Dis 1996, 23:506-514.

18. Godoy P, Tirabochi IN, Severo LC, Bustamante B, Calvo B, Almeida LP, Matta DA, Colombo AL: Species distribution and antifungal susceptibility profile of Candida spp. bloodstream isolates from Latin American Hospitals. Mem Inst Oswaldo Cruz 2003, 98:401-405.

19. Kersun LS, Reilly AF, Ingram ME, Nicholaou MJ, McGowan KL: Antifungal susceptibility against yeasts isolated from pediatric oncology patients. Med Mycol 2008, 46:337-343.

20. Odds FC, Hanson MF, Davidson AD, Jacobsen MD, Wright $P$, Whyte JA, Gow NAR, Jones BL: One year prospective survey of Candida bloodstream infections in Scotland. J Med Microbiol 2007, 56:1066-1075.

21. Pfaller MA, Diekema DJ, Mendez M, Kibbler C, Erzsebet P, Chang SC, Gibbs DL, Newell VA, the Global Antifungal Surveillance Group: Candida guilliermondii, an opportunistic fungal pathogen with decreased susceptibility to fluconazole: geographic and temporal trends from the ARTEMIS DISK Antifungal Surveillance Program. J Clin Microbiol 2006, 44:3551-3556
22. Cheng MF, Yu KW, Tang RB, Fan YH, Yang YL, Hsieh KS, Ho M, Lo HJ: Distribution and antifungal susceptibility of Candida species causing candidemia from 1996 to 1999. Diagn Microbiol Infect Dis 2004, 48:33-37.

23. Laverdiere M, Labbé AC, Restieri C, Rotstein C, Heyland D, Madger S, Stewart T: Susceptibility patterns of Candida species recovered from Canadian intensive care units. J Crit Care 2007, 22:245-251.

24. Pfaller MA, Diekema DJ: Azole antifungal drug cross-resistance: mechanisms, epidemiology, and clinical significance. J Invasive Fungal Infect 2007, 1:74-92.

25. Pfaller MA, Diekema DJ, Gibbs DL, Newell VA, Meis JF, Gould IM, Fu W, Colombo AL, Rodriguez-Noriega E, Global Antifungal Surveillance Study: Results from the ARTEMIS DISK Global Antifungal Surveillance study, 1997 to 2005: an 8.5-year analysis of susceptibilities of Candida species and other east species to fluconazole and voriconazole determined by CLSI standardized disk diffusion testing. J Clin Microbiol 2007, 45:17351745.

26. Chen SC, Tong ZS, Lee OC, Halliday C, Playford EG, Widmer F, Kong FR, Wu C, Sorrell TC: Clinician response to Candida organisms in the urine of patients attending hospital. Eur J Clin Microbiol Infect Dis 2008, 27:201-208.

27. Knechtel SA, Klepser ME: Amphotericin B Resistance: Epidemiology, Mechanisms, and Clinical Relevance. J Invasive Fungal Infect 2007, 1:93-98.

28. Dillon NL, Sampaio SAP, Habermann MC, Marques SA, Lastória JC, Stolf HO, Silva NCC, Curi PR: Delayed results of treatment of paracoccidioidomycosis with amphotericin $B$ plus sulfomides versus amphotericin B alone. Rev Inst Méd Trop S Paulo 1986, 28:263-266.

29. Clinical and Laboratory Standards Institute: Reference Method for Broth Dilution Antifungal Susceptibility Testing of Yeasts; Approved StandardSecond Edition M27-A2. National Committee for Clinical Laboratory Standards, Wayne, Pennsylvania, USA 2002.

30. Nguyen MH, Clancy CJ, Yu VL, Yu YC, Morris AJ, Snydman DR, Sutton DA, Rinaldi MG: Do in vitro susceptibility data predict the microbiologic response to amphotericin $B$ ? Results of a prospective study of patients with Candida fungemia. J Infect Dis 1998, 177:425-430.

doi:10.1186/1756-0500-3-1

Cite this article as: Bruder-Nascimento et al.: Species distribution and susceptibility profile of Candida species in a Brazilian public tertiary hospital. BMC Research Notes 2010 3:1.

\section{Submit your next manuscript to BioMed Central and take full advantage of:}

- Convenient online submission

- Thorough peer review

- No space constraints or color figure charges

- Immediate publication on acceptance

- Inclusion in PubMed, CAS, Scopus and Google Scholar

- Research which is freely available for redistribution

Submit your manuscript at www.biomedcentral.com/submit
Biomed Central 